uncompleted sections and/or withholding of the final grade.

(7) Implementation of the contract is the responsibility of the party of the first part (the student).

(party of the first part)

student signature

(party of the second part)

professor signature

(unsigned party of the third part)

(date)
[Activities, along with evaluation criteria, are listed here.]

Note

1. For a more detailed description of how the ILC may be implemented in classes contact the author.

\section{References}

Freire, Paulo. 1970. Pedagogy of the Oppressed. New York: Continuum. Rogers, Carl K. 1969. Freedom to Learn. Columbus, $\mathrm{OH}$ : Charles E. Merrill.

\section{About the Author}

John F. Freie

John F. Freie is
associate professor
and chair of the
department of polit-
ical science at Le-
Moyne College. He is
former chair of the
board of directors of
Educators for Social
Responsibility. His
major area of study is
electoral behavior.

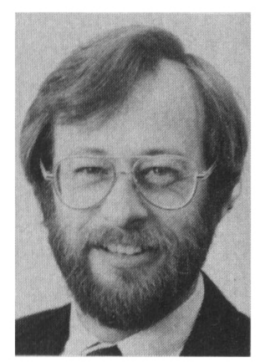

\title{
The Dilemma of Teaching Political Science Research Methods: How Much Computers? How Much Statistics? How Much Methods?
}

\author{
Pamela H. Rodgers, University of Wisconsin-La Crosse \\ Cecilia Manrique, University of Wisconsin-La Crosse
}

One of the goals of many higher education institutions with political science programs has been to incorporate quantitative political analysis in the curriculum as a result of the focus on quantification and empirical research methods in the discipline. Professors and students in political science have had to struggle with the dilemma of determining how much quantification and computer instruction should take place. One of the issues involved was what portion of research methods courses should be devoted to quantification. Teachers had to teach, and students had to learn, statistics in addition to subject matter.

Today, the dilemma is even greater with the advent of computing. Teachers and students face a threefold problem: how much content, how much statistics, and how much computing to teach and learn to make such a course worthwhile for both constituents.

\section{How Much Computers?}

In a world of growing technological knowledge, students in the social sciences are being forced into the computer world with the increased use of word processing, data bases, and on-line electronic media. Political science has seen more opportunities for students to analyze raw data in the areas of American Government and Comparative and International Politics. Despite this, how much knowledge can a faculty member assume of the student? The teacher who decides to incorporate computers and statistical packages in a research methods course will have to recognize different levels at which students will come into the course.

There will be those who already have a strong computer background. Students now coming into college have had a greater experience with computers from grade school and high school as well as from parental guidance (Manrique 1990).

Some students will have a minimal computer background obtained from high school or introductory college computer literacy requirements. This preliminary knowledge will need to be supplemented to guide them through the use of statistical packages because most computer literacy courses ignore the teaching of basic statistical tools. Courses at the introductory level are traditionally geared towards background (what a computer is, what it does, how it works), computing history, and business applications in word processing, spreadsheets, and data bases.

A third group of students would have had no computer background at all. The research methods faculty cannot assume that students will have the necessary background for tackling the course work. A good teaching strategy would be to allow the more skilled students to mentor their 
fellow students who are at a lower skill level.

A faculty member who incorporates computers will need to be prepared, and not relegate computing to an outside reading or one assignment or extra credit points. Computer work needs to be an integral part of the syllabus, graded and acknowledged as an essential aspect of "scientific" learning. The "Introduction to Research Methods" course becomes a stronger critical thinking and reasoning course when computer applications allow students to develop and test hypotheses.

It is frustrating for students to have a teacher who does not make an attempt to learn about the computer and sends students off to the computer center seeking help from "gurus" there. There is more hope for a faculty member who tries to "plod along" with the students for the first time and helps them work out the bugs in an assignment. Even the best-planned exercises and assignments can run into problems upon implementation. Tacking on computer assignments without careful student introduction to the computer and thoughtful preparation can lead to immense frustration on the part of student and teacher. Many times an instructor relegates the computer assignment to the end of the semester when students are not as open to absorbing new material. Careful planning and faculty accessibility are essential to building successful political and social science courses that incorporate computing.

One of the major decisions a faculty member must make is how much of the course should be dedicated to computer instruction. There is no hard and fast rule. The main idea is to reinforce student success in using the computer. The focus should be on integrating the computer portion of learning throughout the semester's coursework. This can be achieved by a brief immersion with computers at the beginning of the course with assignments to reinforce, and build on, that knowledge throughout the semester. It can also be achieved by a series of weekly computer hands-on experiences and assignments throughout the period. Whichever path is chosen, a good one-fourth to onethird of the course may end up devoted to some kind of computer use instruction.

Another decision is whether to use existing data sets or to develop new data sets for the course. Students may collect and analyze raw data from self-made surveys, but faculty can find themselves constrained by the time factor and the often small size of the sample. The ease of using data sets that come with an existing text, i.e., GSS84 data (Norusis) or the SETUPS, ${ }^{1}$ must be weighed against the excitement generated by students using data that come closer to issues of importance in their dayto-day lives.

Decisions by the faculty member will also need to be made regarding the computer system and package to use. Very often the system is determined by what is available in student labs. For the most part the faculty member will have to make a choice between mainframe and personal computers for students to work with. Operating in these two environments can be very different, and it can be difficult to make the transition from one to the other. The computer experience gained by the student in such a course can be valuable since the work place or graduate school would have either one or both systems. On the assumption that the course helps prepare students for graduate school or for work with research institutions, the computer background certainly becomes a major factor in career success. An important issue to keep in mind then is to teach students enough so that they can adapt whatever they have learned to a new situation.

After the faculty member struggles with all of these decisions, a healthy relationship needs to be developed with academic computing personnel on campus. We do not advocate heavy reliance upon academic computing personnel. Computing personnel often face a dilemma with regard to how much help to give. A lot of help means doing everything for the student and faculty, including doing the analysis and suggesting the statistical methods to use. In this situation, everyone loses. The computing personnel feel little self-fulfillment from completing someone else's tasks. At the same time, the student does not learn anything while heavily relying on the expertise of computing personnel. The faculty member does not educate the student and becomes burdened with the knowledge that he or she has released an ignorant, or ill-prepared, student into the work place.

Requiring a little help from computing personnel is a better idea with the development of the project left to the faculty member and student to work out. After all, teacher and student would know the content of their subject better than the computing staff member. The computing personnel can facilitate the project by supplementary training and information on how the statistical package works on the available computer system. Minimum help in data entry and command file creation can be provided, especially when it comes to debugging system errors, but faculty members should also commit time and effort to this as part of their learning experience. The choice of package and statistical method must be mutually agreed upon by faculty and students.

In terms of using prepared data sets in place of creating new data sets, such as using the GSS84 survey included in the Norusis text against making students undertake their own survey, our recommendation is to take advantage of both options. Faculty can use textbook-prepared exercises as well as allow students to complete hands-on research projects. One semester the latter involved a phone survey, data analysis, and report writing for a local newspaper. Another semester we assigned a project analyzing a student survey of computer facilities on campus and writing a report to the Director of Academic Computing. Allowing students to make use of surveys within the institution and evaluating such surveys makes research methods a more meaningful experience.

One major objective of incorporating computing in a political science course is to get the students excited about research possibilities, data analysis, and hypothesis testing using the computer. Another important objective is to provide students with the necessary competence to be flexible in various computing environments. A hands-on computeroriented research methods course can 
give students confidence to undertake their own research projects and enough sense to know where to go for help with problems such as the computer center in a university setting or a data processing group in an institutional setting.

\section{How Much Statistics?}

A teacher in a research methods course must determine how much statistics should be incorporated. Statistics is not a general education requirement in many institutions, and the course could be the first and only introduction to statistics and computers that a student will receive. It, therefore, is a challenge to make it a satisfying, interesting, nonthreatening experience. We have all had students who confess that they "were born without the math gene" and who gravitated to the social sciences to avoid exercising quantitative skills. In recent years, however, more campuses are requiring statistics, and research methods courses have had the same mix of students with no preparation, little preparation, or a lot of background in statistics as we have with student computing skills.

The question of how much time should be spent in brushing up on statistics becomes a crucial point. Some trade-off in course content sometimes has to take place. Introducing concepts of operationalization, levels of measurement, the basics of crosstabulations, dependent and independent variables does not leave much room and time for multivariate regression, time series and trend analysis, etc. Experience has shown that undergraduate students do not necessarily have to run every statistical measure available in the books. The sacrifice in statistical content can be well worth the effort if in the long run the students are able to synthesize the interrelationships among research methods concepts, statistics, and computing, and how these all work together.

Some students may view devoting one-third to one-fourth of the course content to statistics as getting into much more statistics than they bargained for. Some may view dedicating this time period to statistics as an eye-opening experience. They now understand the theoretical concepts they learned in their basic statistics class because they are using real-life situations.

We have all heard horror stories of students who approach computing personnel with the problem: "My instructor gave us this data. We are supposed to analyze it. What am I supposed to do?" Once again, computing personnel get caught in the dilemma of how much help should be given to the student. Many small colleges and universities do not have the personnel and resources to devote to full-time statistical consulting. Therefore, research methods courses have little alternative but to evolve into solid course foundations that will allow students to use computers and statistics in their analysis of social, political, and economic data.

\section{How Much Research Methods Content?}

While research methods concepts anchor the course, computing and statistical applications bring these concepts to life. It is possible to use computers and statistics as instruments for expanding the scope of student learning without sacrificing the contents of research methods. Computers certainly help alleviate the drudgery of number-crunching. Statistical analysis helps bring data into meaningful perspective. But it is still research methods content that brings meaning to empirical work.

We propose integrating computer and statistics assignments throughout the semester with appropriate research methods content. Since most research methods courses tackle the concepts of conceptualization, operationalization, and measurement early in the semester, it becomes relatively easy to make use of computing and statistical tools along with the more traditional research methods approach.

It is also appropriate to tie teaching of computers and statistics to the traditional survey, experimental, and unobtrusive research designs that constitute the core of a research methods course. Students grasp concepts better when they can directly apply design, coding, sampling, and statistical methods concepts to con- crete tasks. Becoming involved in their own research design, students learn from the beginning that it is crucial to a study to formulate a hypothesis and to test it. When designing the survey instrument, students focus on question order and clarity; on coding issues, and on appropriateness of the level of measurement they choose to use. They will also need to identify the various statistical methods they would need to choose in order to analyze the data they would collect. Student appreciation for what they learn comes in the form of reactions such as "I wish I had learned this before. I could have used it for a sociology, psychology, or economics study that I was assigned to do." The student then realizes the interdisciplinary implications and moves away from the compartmentalization of learning.

\section{Conclusion}

It is no longer adequate to teach undergraduate research methods devoid of an understanding of the role played by computers and statistics. It is our contention that students benefit more when computing and statistics are an integral part of a research methods course.

\section{Note}

1. In American politics and public policy the SETUPS were introduced for general class use in 1975 and have been distributed by the American Political Science Association and used widely in colleges and universities throughout the United States.

\section{References}

Daniel, Christopher. 1990. "Political Science as Training for the Information Age." The Political Science Teacher, Fall.

Manrique, Cecilia G. 1990. "Walk Hand in Hand With Me: Centering on Efforts at Internationalizing, Writing and Computing Across the Curriculum." Proceedings of the ACM SIGUCCS User Services Conference XVIII, October. Presents survey data of University of Wisconsin-La Crosse students.

Manrique, Cecilia G. 1991. "Establishing Microcomputer Standards." Proceedings of the 24th Annual Small Colleges Computing Symposium, Morris, MN, April.

Norusis, Marija J. 1991. The SPSS Guide to 
Data Analysis or SPSS $/ P C+$ Studentware. Chicago: SPSS, Inc.

\footnotetext{
About the Authors

Pamela H. Rodgers

Pamela $\mathrm{H}$.

Rodgers is an associate professor teaching political science and public administration courses at the University of Wisconsin-La Crosse. Her research interests

include undergraduate survey research projects on citizen participation, the initiative and referendum, and state and local government issues. She participated in the NSFfunded Quantitative Instruction in American Society Program (QIAS) in 1990.
}

Cecilia G. Manrique

Cecilia G. Manrique, assistant professor of political science, University of Wisconsin-La Crosse, has been affiliated with several institutions in both the fields of computing and political science. Two years prior to joining UWL's political science department, she worked as a user services specialist with UWL's Academic Computing Services.

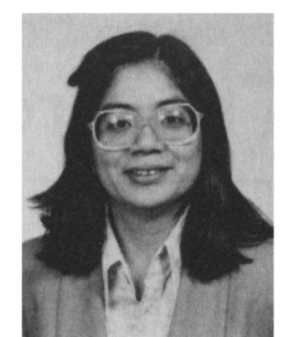

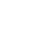

\title{
THE PACIFIC CENTURY New Video and Print Resources for Teaching Asia
}

\author{
by Alex Gibney \\ Executive Producer of THE PACIFIC CENTURY
}

THE PACIFIC CENTURY, a ten-part, ten-hour television series premiering on PBS in the fall of 1992, tries to gaze into the future by looking at the past.

In THE PACIFIC CENTURY we wanted to upset American stereotypes of an exotic and inscrutable orient, while making manifest the strong connections between the United States and the nations of the Pacific Rim. As such, we designed a multidisciplinary series that would mix politics, history, economics, and culture, serving to provide comparative perspectives about contemporary political and economic systems. Undergirding the intellectual solidarity of the series is a group of eminent scholars from diverse disciplines and regional specialties who served as our academic advisors and guides through 150 years of Asia-Pacific history.

To a political scientist such a blend should seem perfectly natural. For it is impossible to understand the modern Asia-Pacific region without a grounding in the regional history of the past 150 years. For example, in the first program, "The Two Coasts of China," we look at the historical tension in China between the insularity and self-sufficiency of the interior and the cosmopolitan character of the coast. It is a tension that still dominates China today. In other programs concerned with Japan, Indonesia, and Vietnam, we show the emergence of strong national movements in response to western colonialism which still color the nationalistic character of the political economies of Asia today.

One cannot understand contemporary Asia (or Europe) without understanding the marriage of convenience between politics and economics. In effect, with this series we sought to rescue an interpretation of Asia from analysts who argued that the capitalist societies in Asia were "just like us." But in highlighting differences, we did not look to "culture"; rather we sought to explain differences in political systems. We tried to shy away from an over-reliance on "cultural" distinctions because we believe that many Americans tend to use "culture" to explain away high-speed economic growth in Asia. At the same time, culture in its widest and truest sense-the totality of socially transmitted history, behavior pattern, arts, beliefs, institutions-is important. We have not tried to ignore cultural differences; we have simply tried to set them in a broader political and historical context.

Most importantly, we have tried to look at Asia from a regional perspective. We believed that prior series on individual countries had been too atomized. In an era of rapid communications and global economics we felt it was important to try to see the Pacific as an interrelated and interdependent region.

This regional approach would bring home to American students the sense of how the Pacific has penetrated their daily lives-from Japanese factories in the U.S. to round-the-clock television coverage of the 1989 demonstrations in and around Tienanmen Square. We also believed that this approach would give students a heightened awareness of the Asian-Pacific character of the United States, as immigrants from Hong Kong, Taiwan, South Korea, and Southeast Asia pour into our major cities. 